\title{
Subjetividad y anagnórisis: un repaso por la poesía de Antón Arrufat
}

En este artículo se analizan un conjunto de poemas escritos por el autor cubano Antón Arrufat reunidos y publicados en sus libros Repaso final (1964) $y$ Escrito en las puertas (1968). Además de rescatar estos textos que, debido a la proscripción sufrida por el autor desde 1968 hasta principios de los 80, han tenido muy poca circulación y escasa recepción crítica, la lectura que aquí se realiza busca señalar los desacoples entre la concepción de subjetividad que proponen estos poemas y aquella promovida por una política cultural estatal dirigida a la construcción de un sujeto moralmente superior, cuyo modelo se condensó en la figura del hombre nuevo guevariano. De esta manera este ensayo intenta contribuir al estudio de las complejas relaciones entre literatura y política durante los años inmediatamente posteriores al triunfo de la revolución cubana.

Cuando se habla del escritor Antón Arrufat, enseguida, casi sin excepciones, vuelve la misma anécdota: en 1968, en ocasión del IV Concurso literario convocado por la Unión Nacional de Escritores y Artistas de Cuba (UNEAC), su obra Los siete contra Tebas (1968) es seleccionada por un jurado internacional para ser galardonado con el Primer premio de teatro. En esa misma edición del concurso el poemario Fuera de juego, de Heberto Padilla, se lleva el Premio Nacional de poesía. Pero las autoridades culturales de la UNEAC expresan su desacuerdo con la decisión del jurado y firman una declaración manifestando que estos dos premios habían "recaído en obras construidas sobre elementos ideológicos francamente opuestos al pensamiento de la Revolución" (Comité Director 9). Más aún, pese a que llegan a imprimirse, en la primera página de estos libros el Comité Director hace constar su "Declaración" de repudio e impide, en los hechos, que estos dos textos que, según afirma, "sirven al enemigo" (9), sean distribuidos o que la obra sea puesta en escena. Lo demás es historia sabida: el premio significó, en realidad, un castigo para ambos escritores. Para Arrufat la pena consistió en su confinamiento en el oscuro sótano de una biblioteca municipal y su silenciamiento durante catorce años. Para Padilla, la distinción de la UNEAC fue la antesala del tristemente célebre caso que lleva su nombre y de la noche cultural que se conoció como el "quinquenio gris" (Fornet 1987). Como resultado, este 
episodio que dejó a la vista el férreo control estatal sobre la actividad cultural de la isla y que produjo un quiebre en el apoyo de la izquierda intelectual internacional a la revolución cubana, marcó un antes y un después en la larga trayectoria del autor de Los siete contra Tebas. Así, cuando a fines de los 80 llegó el momento de su rehabilitación por parte de la oficialidad y su talento literario volvió a destacarse a través de reconocimientos tales como el Premio Nacional de Literatura de Cuba en el año 200o, las consecuencias de aquel infortunado acontecimiento en la biografía de Arrufat habían sido de tal gravedad que vuelve superflua la pregunta acerca de por qué queda tanto por decirse acerca de el resto de su obra, aquella que escribió cuando todavía no había protagonizado el escándalo por el que sería luego recordado. Resto, residuo, exceso sobrante en la vida de este escritor que se interrumpe y se reinicia como otra a partir de ese funesto momento en que, como ocurre a los personajes de la tragedia, una disposición estatal tan arbitraria cae sobre él como fatum y transforma radicalmente su identidad: "No sólo estábamos muertos en vida - recuerda Arrufat - parecíamos no haber nacido ni haber escrito nunca" (Virgilio 42). Es, por tanto, al rescate de algunos textos fundamentales pero muy raramente comentados, previos a Los siete contra Tebas, a lo que este artículo querría contribuir. Se trata de los trabajos de un Antón Arrufat muy joven, que, por la calidad de su producción ha conseguido ya, desde comienzos de los 6o, ocupar un lugar definitivo en "el centro de la cultura cubana" (Barquet 61). Se trata, asimismo, como ocurre con otros intelectuales de la generación del 50, de experiencias literarias que tienen lugar en el transcurso de los primeros años de la revolución, con la que el escritor mantiene una relación de fascinación pero también, progresivamente, de crítica, según esta va endureciéndose en sus postulados e interviniendo cada vez más capilarmente la cultura. En particular quiero detenerme en dos de sus poemarios, Repaso final (1964) y Escrito en las puertas (1968). Debe hacerse la advertencia de que Repaso final suma a su corpus los poemas publicados anteriormente en En claro (1962), presentados ahora bajo este mismo título en la primera sección del poemario de 1964. A su vez, a excepción del profético "Ellos", todos los poemas de la sección tercera de Repaso, titulada "Ejemplos y epigramas", reaparecerán en Escrito en las puertas bajo el encabezamiento "En la casa de Marcial, 1963". En suma, los dos libros que he seleccionado recopilan una producción poética que abarca un arco que se extiende entre 1961 y 1968. Los he escogido pues veo en este conjunto de textos una intervención pública en una cuestión que desde principios de los 60 se ha vuelto acuciante para el gobierno: la producción del sujeto de la revolución. Este tema fue de vital importancia en la Cuba de esos años no sólo porque, 
como en cualquier régimen político, las condiciones de gobernabilidad dependen de la fabricación de una subjetividad específica, sino sobre todo porque en la versión cubana de la teoría marxista, el factor subjetivo - y no sólo los factores objetivos - constituyó una variable decisiva en la lucha insurreccional: el estímulo y desarrollo de cualidades morales como la voluntad, el coraje, la disposición al sacrificio y la capacidad de organización - se decía - harían posible crear, y ya no sólo esperar, la situación revolucionaria. En esta perspectiva, el movimiento de la historia no sólo tenía que ver con las fuerzas materiales, sino también con una determinación ética que, inspirada en un ideal trascendente, lograría a través de la acción consciente adelantar las condiciones necesarias para producir la transformación buscada.

Dicho esto, una lectura atenta a la complejidad que caracteriza el período debe dar cuenta, tanto al interior del campo de la política como en el campo artístico-cultural, de las ambivalencias y los doble juegos que se dieron entre el llamado a la creación de lo nuevo - que implicaba la crítica del pasado, la inauguración de instituciones, la exploración de formas estéticas - y esta exigencia de reconocimiento de modelos previamente prescritos, que señalaban, para esa creación, el camino a seguir. Así, por ejemplo, si la proliferación de nuevas revistas - Lunes de Revolución, Casa de las Américas, Unión, El caimán barbudo- y editoriales - Ediciones R, la UNEAC, la Editorial Nacional, las ediciones de la Casa de las Américas eran leídas por los intelectuales como signos de que el gobierno revolucionario apoyaba la actividad cultural y subsanaba las enormes dificultades para publicar que hasta entonces había debido afrontar el escritor cubano, la progresiva exigencia de homogeneización de la producción artística, y en ciertos casos, su silenciamiento, indicaban también que esa política cultural no estaba reñida con los cierres ideológicos. Asimismo, también los propios intelectuales experimentaron este conflicto entre la voluntad de ruptura con la tradición y la búsqueda de nuevos lenguajes, por un lado, y una relación problemática con el pasado. Este conflicto se torna visible en un amplio abanico de cuestiones que abarcan, desde la obsesión por la reescritura de los textos fundacionales del archivo nacional (González Echevarría, "Humanities" 206-7.), hasta la consagración de la literatura al deber de rememoración y testimonio del sacrificio de los héroes - y aquí el poema "El otro", de Roberto Fernández Retamar, escrito el I de enero de 1959, inauguraría la serie. 
En ese marco de tensiones y poco después de la polémica por la censura al filme $P M$, Fidel Castro pronuncia en la Biblioteca Nacional su ya legendario discurso conocido como Palabras a los intelectuales (1961). Allí, se recordará, quedan definidos los contornos de la cartografía revolucionaria: "Dentro de la revolución todo, contra la revolución nada" (14). Lo cual quiere decir, entre otras cosas, no sólo que la revolución no tiene fuera, sino, sobre todo, que el único "dentro" admitido será el que ofrece ella misma. Tal "estriamiento" del espacio (Deleuze y Guattari 483 y ss.) requiere, fundamentalmente, de la creación de una lengua específica, y la revolución se dará en una lengua propia que funcionará como único criterio de inteligibilidad: toda experiencia que no pueda ordenarse, disponerse y clasificarse en ese sistema de evidencias compartidas puede ser ahora entendida como un desarreglo de la subjetividad que perturbe la producción de un sentido que busca ser normalizado -transparente, monosémico y público -. El hombre nuevo que comienza a construirse tras el triunfo contra la dictadura de Fulgencio Batista será el hablante nativo de esa lengua colectiva, porque en él los pliegues de la individualidad y el goce privado habrán sido desterrados como las últimas taras de la cultura burguesa. En esa tarea intervendrán la escuela y el trabajo, dispositivos que le darán el nombre justo a cada experiencia, ordenarán las pasiones y disciplinarán los cuerpos. La materia sobre la que operará esta ascesis será la voluntad, que ahora requiere ser dirigida hacia un fin exterior a sí misma: la construcción de una sociedad revolucionaria. Desalojar la intimidad, volcarse hacia las necesidades colectivas olvidando la mezquina preocupación por las propias es la consigna: tal vez la imagen que mejor ilustra esa exigencia de entrega de sí, de esa pulsión hacia el afuera, es la multitud de jóvenes, apenas adolescentes, que, alistándose voluntariamente en la campaña de alfabetización de 1961 para trabajar como maestros en las zonas más pobres y remotas de la isla, salen de sus casas familiares, arriesgando - y en algunos casos, hasta perdiendo - sus vidas frente a las milicias contrarrevolucionarias. Pero esta "conversión revolucionaria" (González Echeverría, "Biografía" 250-52.) no es espontánea ni aleatoria, sino que debe seguir cierto entrenamiento que conduce a un estadio moralmente superior. De ahí que este particular modelo cubano de construcción del socialismo basado en el desarrollo de la conciencia y el incentivo moral halló sus imágenes más elocuentes en la escena pedagógica (Kapcia; Mac Donald; Cheng). "La sociedad en su conjunto debe convertirse en una gigantesca escuela", decía el Che Guevara en su carta a Carlos Quijano, más conocida como "El socialismo y el hombre en Cuba" (38). En los hechos, durante los primeros años de la revolución esta metáfora se tradujo en un verdadero plan de 
transformación de la conciencia "desde arriba" encomendado a un sinnúmero de instituciones específicamente creadas para este fin que sumaban, a la alfabetización universal, el acceso igualitario a los bienes culturales (Miller). Así, tan pronto como en 1959 se crean Casa de las Américas, la Imprenta Nacional, el Instituto de Arte e Industria Cinematográfica (ICAIC), el Ballet Nacional de Cuba; en 1960, la Orquesta Sinfónica Nacional; en 1961, el Consejo Nacional de Cultura y la Unión de Escritores y Artistas de Cuba (UNEAC); en 1963, la Comisión Nacional de Monumentos. Paralelamente se nacionalizan las emisoras de radio y televisión y se inaugura en 1962 el Instituto Cubano de Radiodifusión; se llevan a cabo campañas de difusión masiva de música, libros y revistas, se crean unidades de cine móvil para llegar a poblados que, por primera vez, conocen lo que es un filme. Pero además, esta intervención basada en la distribución del capital cultural entre la sociedad cubana en los primeros años de la década del sesenta se complementó con un llamado al trabajo voluntario que fue concebido, también, como una instancia de formación. La educación en un sentido amplio, que incluyó no sólo la distribución igualitaria de contenidos sino también el desarrollo de una conciencia moral era por tanto el ámbito en donde se jugaba la efectiva realización de la revolución. Así, por ejemplo, en ocasión de la inauguración en 1967 de un internado y cinco círculos infantiles, Fidel Castro declara en la localidad de San Andrés:

...la vida de todos los niños estará perfectamente organizada, estará perfectamente atendida. Irán a los círculos por la mañana - bien temprano - y regresarán a sus casas al atardecer. Y cuando ya tiene edad para ir al primer grado, entonces su vida entera estará organizada alrededor de la escuela. Allí tendrán los estudios, los campos deportivos, la alimentación. Irán los lunes y regresarán los viernes, y tal vez los sábados. ... Nosotros no tenemos la menor duda de que los muchachos van a estar ansiosos siempre de que llegue el lunes para ir a la escuela, porque en la escuela tendrán todas las facilidades, todas las instalaciones, tendrán su vida perfectamente organizada de una manera agradable, de una manera atractiva. ("Discurso")

Hay en estas palabras una convicción profunda acerca de la coincidencia "natural" entre la necesidad que la Revolución tiene de construir su propio sujeto y el deseo de "los muchachos" de responder gozosamente a esa demanda; o también, dicho de otra manera, se asume el necesario encadenamiento entre un hecho - la creación de la escuela y su necesaria consecuencia - el deseo de asistir a ella. La idea de una "arcilla maleable" de la que hablaba el Che en su carta al director de Marcha, con la que "se 
puede construir al hombre nuevo sin ninguna de las taras anteriores" ("El socialismo" 45) muestra la particular concepción de materialismo que sostiene el gobierno revolucionario ${ }^{2}$ : la combinación de circunstancias político-sociales, estímulos morales y acción pedagógica permiten augurar como resultado, según una inferencia ciertamente determinista, un cierto modelo de hombre.

Las interrogaciones poéticas de Antón Arrufat atacan a esta noción de subjetividad. Puesto que este materialismo descansa en la idea de la existencia de leyes que se conocen de antemano, la dirección del curso de la historia, su destino no es más que una versión disfrazada de idealismo. En su lugar, Arrufat va a oponer un materialismo que rechaza toda linealidad - tome ésta la forma del racionalismo y la necesidad, del origen y el fin preestablecidos, de la causa y el efecto - reivindicando en cambio el movimiento y la contingencia que permiten la autocreación en el desvío, en el encuentro y en la relación con lo/s otro/s. Dice en uno de sus poemas de Repaso final:

Creo en la verdad objetiva,

creo en lo que conoceré,

creo en la materia,

creo en las fuerzas contrarias,

$$
\text { Amén. (I47) }
$$

Esta pequeña "Oración diaria" expone en pocas palabras una fe que apuesta simultáneamente a "la verdad objetiva" y a "lo que conoceré", al devenir de una materia que es objeto de permanente tensión entre fuerzas contrarias, abriéndose así a lo imprevisible que - veremos - es también lo que se repite, lo que retorna.

Los textos de Arrufat que estamos leyendo aquí rehúsan a un modo de conocimiento sostenido sobre pares dicotómicos tales como lo objetivo y lo subjetivo, el afuera y el adentro, el cuerpo y la conciencia, las cosas y las palabras, en los que el primer término opera como principio de verdad. Por el contrario, el poeta elige colocarse siempre en los umbrales, allí donde es más fácil entender que la materia no se manifiesta como estados definitivos del ser, sino como flujo, como un hacer o un proceso de permanente diferenciación de sí mismo. Estos espacios liminares son, a veces, las puertas - Escrito en las puertas -; otras, las murallas - en Los Siete contra Tebas -; otras, las cajas - La caja está cerrada (1984). Lejos de separar dimensiones contrarias, el emplazamiento desde el cual habla Arrufat es siempre un paso en el que se revela la imposibilidad de trazar un límite que escinda lo otro de lo mismo, el presente del pasado, lo 
idéntico y lo diferente. En Escrito en las puertas ese pasaje no sólo es entendido de acuerdo al sentido que la palabra asume en su función de sustantivo, sino sobre todo como verbo, como acción que remite al movimiento. La variabilidad, el cambio y el irreversible paso del tiempo son el tema de estos textos; no es azaroso, entonces, que el poema que inaugura este poemario lleve por título "Uno de paso". La explícita referencia a Heráclito, filósofo cuya doctrina aparece muy tempranamente rigiendo las búsquedas de Arrufat ofrece la clave de lectura de estos textos poéticos en los que la condición del hombre es pensada desde la metáfora del viaje y el viajero, de un tránsito o devenir que no termina sino con la muerte. ${ }^{3}$ Se está siempre pasando, y por tanto, siempre atravesando puertas. El poeta no puede hablar más que desde ese estado perentorio, fugitivo. En ese poema inaugural leemos:

Recorro la ciudad de los viajeros.

En las esquinas todos dicen adiós.

En vano se estrechan con un saludo

y repiten sus nombres: dicen adiós.

Dejaron sus cosas dispersas y salieron

en la noche, temprano, sin maletas.

Tú los despides, Heráclito, en la puerta,

en los andenes, en el amor difunto.

Me voy, me voy. Somos mortales. (9)

Ser mortal es estar sometido al transcurrir del tiempo, y por tanto, aunque no lo sepamos es estar yéndonos siempre: nos estamos despidiendo en el momento mismo en que creemos estar presentándonos con nuestro nombre. En 1969, apenas poco tiempo después del escándalo producido por el premio a Los siete contra Tebas, Arrufat vuelve a meditar sobre el legado del Oscuro de Éfeso y escribe el largo poema "El río de Heráclito" (Huella en la Arena 119). Ahora la reflexión en torno al devenir va desplegándose en el transcurso de un viaje habanero en ómnibus.

El poema comienza cavilando acerca del carácter mortal de los hombres que en apariencia se contrapondría a la supuesta condición maciza, sólida, de la ciudad:

Mas tú, Habana, eres segura, edificada

como la eternidad para que nos recibas,

nos miras pasar, y creces con nuestro adiós.

Miré tranquilo. El ómnibus corría. Era

hermoso saber que todo perduraba. 
Donde habías estado despidiéndote, perduraba, piedra o hierro. Pensé que el hombre, con su pequeña muerte diaria en el costado, en el bolsillo de su camisa de fiesta, hacía perenne la ciudad, sacándosela de su costilla. (120)

La voz poética describe las distintas estaciones del itinerario: una panadería, un jardín, una calle. La ciudad se levanta como una evidencia compacta e incuestionable, como una construcción destinada a permanecer más allá de las vidas efímeras de sus habitantes, y por un momento ese pensamiento parece ofrecer un consuelo. Pero según avanza el poema - y el ómnibus -, el reconocimiento de esta condición fluyente de los seres va incluyendo en su registro, progresivamente, también a las cosas:

Los viajeros anónimos, desconocidos, también se movían. Quise recordar, detener el momento. Entonces me di cuenta: el banco donde estabas era una larga nave en la tierra de los jardines: parte mientras la estatua cae, y los cueros azules ennegrecen como una reliquia. ¿En qué museo estás y qué puertas se cierran? (121)

Quien habla en el texto constata que todo es, como él mismo, pasajero. No es posible, así, hablar de un origen, de un comienzo en el que la historia empieza: todo se transforma allá afuera del autobús que, a su vez, nunca es el mismo porque jamás detiene su marcha. Incluso las palabras muestran su incapacidad para referir a algo que resista a este movimiento, llámese lo absoluto, lo incondicionado, o, como ha ocurrido más frecuentemente, el ser. El lenguaje está también afectado por esta inestabilidad: “...constituye el modelo más sobresaliente del principio de Heráclito", dice George Steiner, dado que "[s]e altera en todo momento del tiempo vivido" (33). El nombre no es transporte de un sentido conceptual, fijo y trascendente, sino que también él es transportado, usado en contextos diversos, modificado en el transcurso de ese tráfico:

Ahora las cosas eran iguales a nosotros:

se acercaban a los cristales, se perdían después, después no estaban. Estar fue una palabra 
y se deshizo en mi garganta, rodó al pasillo,

unos pies la aplastaron. (122)

Regido igualmente por la ley del cambio y la transformación, lo propio del lenguaje es, como el cuerpo, su pasar, su imbricación activa en la configuración de una experiencia que es única e irrepetible. En rigor, si lo propio del signo es traer su referente a la presencia, toda presencia, incluida la de los signos como cosa material, es el signo de una ausencia inminente. Pues, si como advirtió Heráclito, todo fluye - panta rei - lo que se nos presenta no es más que manifestación de lo que está dejando de ser, de lo que fue. Pero semejante consigna introduce ya una cavidad, un pliegue que supone una afrenta a la lógica de la identidad ¿Quién es el que habla, quién el que está ahí cuando se dice "yo", "estoy" o "ahora"?

En "Repaso final" puede leerse el poema "Agnición", en el que se sugiere que la posibilidad de acceder a un saber sobre sí mismo reside en los otros. La agnición o anagnórisis está aquí supeditada a la memoria ajena, de modo tal que son los otros quienes, con su testimonio, ponen a salvo mi existencia, rescatándola (rescatándome) tanto de la muerte como de mi propio olvido. ${ }^{4}$ Dice:

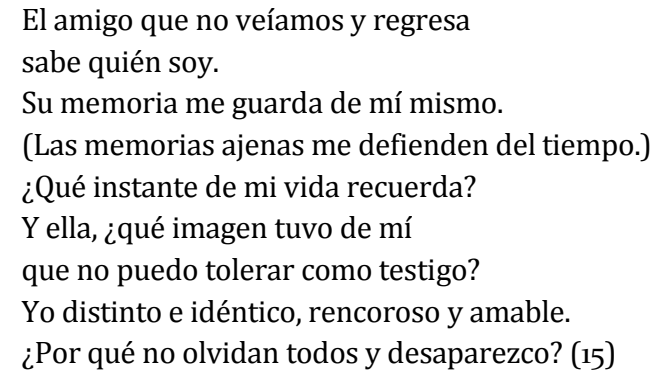

Si fuimos testigos de aquellas experiencias en las que creímos ser protagonistas, no tenemos, sin embargo, ningún privilegio a la hora de narrarlas: nos es privado el derecho de ser los autores excluyentes de nuestra propia historia, y hasta para desaparecer dependemos de los otros. "Yo" no puede ser fundamento o causa eficiente de nada, puesto que su nombre refiere a un vacío. Dice en el poema "La causa":

No eres nada

mientras te busco,

te apagas como un disco que termina.

Si te busco no eres nada: 
tan sólo yo mismo. (53)

Es también de la disolución del Autor en el río heracliteano, que es el de la semiosis infinta, de lo que hablan los poemas de Arrufat; y sin dudas ameritaría una investigación aparte responder a la pregunta acerca de las condiciones de recepción en la isla para una poética como la suya, en un momento en que, por ejemplo, el prestigio creciente del testimonio reordenaba el sistema de los géneros literarios al punto tal de que en 1970 Casa de las Américas creaba un premio específico para esta categoría. Muy lejos de profesar esa fe en un sujeto que, estando en el escenario de los hechos y en el origen de su propio discurso, puede dar cuenta de lo que pasa/lo que pasó, Arrufat vacía ese lugar desde el cual, quien lo ocupa, puede legítimamente reclamar creencia: el sujeto que configuran sus poemas es, recordémoslo, apenas uno de paso. Pero, ya lo hemos dicho, tampoco se trata de una confirmación celebratoria de la subjetividad burguesa como entidad creadora autónoma e individual. Por el contrario, en Arrufat la subjetividad está ligada a la inscripción de lo otro en lo mismo, a la diferencia como rasgo constitutivo de la identidad, al "uno es dos" heracliteano. Es el otro, en un texto ajeno, quien puede narrar mi propia historia.

Por eso la anagnórisis está ligada a la reescritura. Margarita Mateo Palmer se ha detenido ya en señalar las peculiaridades de lo que el autor de Las pequeñas cosas ha llamado "estética de la superposición" (16), y ha visto en ella una de las claves de lectura de su obra. En su trabajo la autora sigue la pista del vínculo entre superposición y comprensión, destacando el hecho de que, para Arrufat, superponer es una operación intelectual que permite "al lector arribar a un juicio más enriquecido en su perspectiva crítica" (16). Así, dice Mateo, un procedimiento típico de Arrufat sería el superponer un texto a otro para poder entender mejor a éste último, anulando la datación temporal y la autoría de cada uno de ellos de modo tal que, fundidos en una especie de palimpsesto, conducen, no a la pérdida de identidad, sino a su reafirmación, lograda "en la fecundidad de la relación dialógica" (18). Por mi parte considero que la idea de "reafirmación" resulta confusa, pues podría dar a entender que la identidad propia es ya un contenido originario o sustancia primera sobre la que se acumulan, como las capas de óleo en una pintura, otras capas. Más bien en el encuentro del yo con el otro - y con ese otro que es un texto - tiene lugar el proceso de agnición al que refiere el poema, en el sentido de que el otro aporta un conocimiento acerca del yo que éste ignoraba, pero que se ilumina en el momento mismo en que tiene lugar el contacto entre ambos. Dicho de otra manera, paradójicamente lo que ese encuentro 
revela es que no hay un yo que lee, sino que ese yo es materialmente creado como retorno del acto de lectura. La causa es posterior al efecto puesto que el yo es, finalmente, un lugar de hospedaje provisorio para múltiples voces ajenas. En ambos poemarios, la abundancia de muestras de la fascinación de Arrufat con las máscaras, los espejos, la fotografía, la figura de Proteo, en fin, con todo aquello que permita interrogarse la idea misma de fidelidad a un arquetipo debe interpretarse en este misma dirección. Si esto es así, debe leerse todo Repaso final a la luz de la advertencia lanzada por el poeta apenas abrimos el libro, en el primer poema, titulado precisamente "Fidelidad". En una alusión crítica al idealismo platónico, leemos:

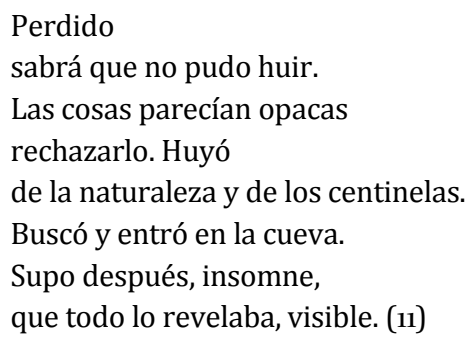

La voz lírica describe un recorrido inverso al que emprende el que busca la verdad en la alegoría de la caverna. Como es sabido, en La República Platón expone el proceso que debe atravesar el sabio para alcanzar el conocimiento de lo auténticamente real, eterno e inmutable: las Ideas. Así, el filósofo es aquél que, apartándose de los datos sensibles por no reflejar fielmente al mundo, huye de las falsas creencias por medio de las cuales el hombre se vincula con la naturaleza y con la ciudad para contemplar las esencias y comunicar este conocimiento a quienes siguen prisioneros en la caverna, liberándolos. Para Arrufat, en cambio, la verdad requiere de la realización del trayecto contrario: si en un principio el idealismo ha regido nuestra relación con las cosas, y entonces no es en ellas en donde nos hallamos a nosotros mismos porque las Esencias habitan en el mundo trascendente, nuestra búsqueda de la verdad nos lleva, finalmente, a descender hacia la cueva modesta del conocimiento humano, en donde entendemos finalmente que compartimos la misma condición temporal, mutable y perentoria que el resto de las realizaciones momentáneas de la materia. 
Pero volvamos a la cuestión de la anagnórisis y la reescritura. Al hablar de la materialidad de la literatura Arrufat nos insta no solo a tomar en cuenta sus condiciones de producción tales como las circunstancias históricas y sociales, sino, fundamentalmente, a reparar en el hecho de que también ella participa del ciclo dialéctico de destrucción/producción heraclitiano, fabricando o engendrando con sus propios medios - el lenguaje - otra cosa, de la que son muestra las infinitas posibles reescrituras de un texto que se separan de la versión anterior (no podríamos decir del "original") por una diferencia apenas perceptible. Todo texto, así, contiene ya sus dobles, todo libro es, como el río, uno mismo y otro simultáneamente.

Reescribir es, entonces, dar muestras tanto de esta capacidad creadora de la literatura como del hecho de que ella forma parte de esta circulación perpetua de la materia. Esto quiere decir que el sentido de un texto va revelándose a través de sus infinitas transformaciones. Dicho de otra manera, un libro no debe entenderse como texto cuyo sentido podría captarse y reducirse mediante los procedimientos propios de la crítica o la pedagogía sino como un acontecimiento o realización discursiva que como advirtiera Foucault en su segundo "Prólogo" a la Historia de la locura en la época clásica - precede y produce a su Autor y a su Sentido (4-5).

Así, para Arrufat la subjetividad tiene lugar en la imposible resolución de la tensión entre repetición y novedad, tensión que la idea de la revolución como retorno o recuperación de un origen más puro y prescripción moral del ideal de Hombre Nuevo debe necesariamente negar para resultar verosímil. La revolución no es regreso al principio, al lugar en el que la historia se repliega y donde habitan los "ilustres ancianos" y los padres de la patria. No es una permanencia sino una marcha dinámica, un estar pasando que no conoce ni el reposo ni la fosilización en panteones destinados al recuerdo de los venerables. En "Definición", uno de los escasos poemas que dedica explícitamente al tema de la revolución, Arrufat lo explica con contundencia:

Junto a los que se van

los que permanecen.

Junto a mí la Revolución

que nada tiene que ver con ustedes,

ilustres ancianos,

babeantes y fanáticos. (Repaso final 145)

La administración estatal de la memoria, la demarcación del espacio según fronteras que recortan lo que queda dentro o contra y la voluntad oficial de 
reordenamiento de los calendarios a partir de fechas en las que el tiempo supuestamente comienza de nuevo rechazarían este constante movimiento de destrucción y creación a partir de lo mismo que para Arrufat caracteriza la vida. De manera más o menos directa, lo que Arrufat declara se coloca a contramano de ese escenario público preñado de voces en las que resuena lo que Derrida llamaría el "tono apocalíptico" de quien quiere dar a entender no que lo que expresa es la verdad acerca del fin, sino que la verdad que dice es ella misma el final, que su develación es al advenimiento o instauración del fin (55). Debe entonces leerse como una humorada que en ese mismo escenario Arrufat titule su poemario Repaso final, título que constituye un oxímoron, porque afirma que finalizar es un pasar otra vez (que es finalizar que es un pasar otra vez que es finalizar...). Pasar es, así, traer otra vez el pasado; y, por tanto, hacer audible la voz de los muertos. Para Arrufat es el poeta ese que re-pasa, y en ese rescate de los restos se cumple su función política. La deuda con la antigüedad clásica, visible en toda la obra del autor de Los siete contra Tebas, se muestra también aquí: el trabajo del poeta, instruido por las musas, hijas de Mnemosine, forja la cohesión y la identidad de la polis sobre el recuerdo de las hazañas de los héroes. Sólo que en Escrito en las puertas - como ocurre también en Los siete contra Tebas - Arrufat prefiere recuperar la voz de los seres simples, hombres y mujeres del pueblo. Sigamos al poeta en su excursión por la ciudad: en "Uno de paso" la voz lírica da inicio a su viaje. "Recorro la ciudad de los viajeros" (9), anuncia en el primer verso del primer poema, y a partir de entonces el libro puede leerse como los apuntes de ese deambular por una urbe en la que, como la Habana del viaje en ómnibus, todo está en movimiento. El poeta es el que se mueve por las calles de una ciudad que es la suya y que habita desde siempre; las recorre, pero en verdad no registra lo que se da a ver, sino los indicios de lo ausente en lo que hay. Escenario de la vida, el espacio de la polis tiene la forma de un guión teatral: en él cada actor tiene asignado una entrada, en el doble sentido de parlamento y puerta. Cada personaje dice su parlamento cuando hace su entrada, cada entrada hace aparecer un personaje por la puerta. 0 bien: lo que cada habitante de la ciudad tiene para decir en ese drama colectivo ha sido ya escrito en las puertas. Preguntamos entonces: ¿habla el habitante, o la inscripción de su puerta ya ha hablado por él? ¿Quién habla cuando habla la puta, el hijo, Luisa y Miguel, la lavandera, el médico, y otros cuyas palabras recoge el poeta? ¿Acaso lo que dicen no es también un repaso o re-cuento de lo ya dicho, vuelto a decir otra vez por el ocasional ocupante de cada habitación? Sí, a condición de que se reconozca que este volver a decir no es un decir lo mismo sino una repetición, en el sentido de Deleuze. Como sostiene este autor en Diferencia y repetición (2002), la 
repetición no tiene que ver con la representación de algo - una Idea previamente existente: la repetición pervierte la lógica de lo uno/lo mismo al revelar la multiplicidad de la significación (423-25). La repetición, entonces, no es la oportunidad de confirmar la fidelidad a algún enunciado fundamental, sino de emergencia de lo nuevo.

Pero, si seguimos en la dirección de esta regresión a un origen imposible ¿no cabe, ahora, apuntar el dedo hacia el poeta mismo y preguntarle quién habla cuando él habla? La respuesta llega al final del viaje, justo cuando el viajero se adentra "En la última puerta":

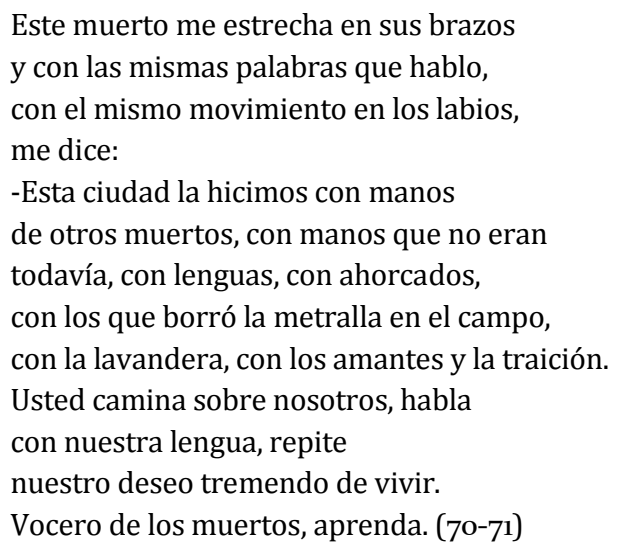

En esa última puerta se cumple la agnición: y entonces, al fin, sabemos que no era el poeta quien hablaba, sino los muertos. 0 , lo que es lo mismo, la palabra pronunciada por otro, el lenguaje como producción material que subsiste a sus productores y queda como sedimento en el río de la historia, resto indisoluble y listo para reemerger, para ser reproducido en el momento menos esperado, pero esta vez diciendo otra cosa. Así, lo que muere es, en verdad, lo que queda, y de aquí que la agnición esté ligada a la herencia. De hecho, en el campo del derecho sucesorio agnición es la declaración del consentimiento o aceptación expresa de los bienes a heredar por parte del heredero: no se hereda por obligación, sino porque se acepta. Esto significa, también, el derecho a apartar y rechazar. 0 a restituir lo que otros han elegido olvidar, ocultar o negar al recibir el legado de los antepasados. Por eso la importancia de "En la puerta del siboney", primera estación en la que se detiene el poeta peregrino después de notificarnos de su intención de recorrer la ciudad: su viaje es un desplazamiento por el espacio, pero antes que nada, por el tiempo. En esa arqueología, es al indio siboney, primitivo habitante de esas tierras 
exterminado rápidamente por los conquistadores españoles, a quien escucha el poeta. $Y$ dice:

Perdimos nuestras piernas en el río,

se pudrieron en las arenas nuestras manos,

y no había oro.

Esta era una tierra pobre y de paso.

Entre los dedos de vuestros padres

se extinguió nuestra raza.

..

Les dejamos el nombre de las ciudades,

palabras que pronunciarán diariamente.

Los débiles, los sacrificados

dejan siempre su ofrenda.

¿Quién negará que camina sobre nuestros cadáveres?

Que no les sea negada la felicidad.

Que nada turbe vuestra pesadilla, hombres blancos. (10)

El poema restituye una pieza que ha sido sustraída de la herencia: al siboney como legatario. No hay sucesión de herencia sin posibilidad, por parte del recipiente, de interrupción, alteración - re-escritura - dijimos. Nuevamente es la fidelidad lo que se pone en cuestión: el poeta no sólo rompe con la ilusión de la serie sucesoria, sino que además revela que esa serie está desde siempre ya rota, fragmentada, llena de intervalos y lagunas. Con esas palabras de la tribu, el heredero siempre puede actuar y hacer(se) con ello otra cosa distinta a su familia, su cultura, su identidad, su historia. Así, lo legado jamás puede entenderse como una predestinación. Por lo contrario, recibir una herencia es un proceso de agnición, de advenimiento de una subjetividad toda vez que es un nuevo actor quien emerge de sus acciones. No hablaba de otra cosa Los siete contra Tebas: Polinice y Etéocles reciben la herencia de la casa de Layo, pero hacen con ella dos cosas muy distintas. Mientras que Polinice reclama toda su herencia - el trono, la fortuna - Etéocles ha renunciado a parte de ella al repartir sus bienes con el pueblo tebano. Es, en este punto, un traidor a su linaje, dice Arrufat (Bejel 8). Sin embargo, si bien Etéocles ha fundado otra justicia y ha socializado la riqueza, apartándose del derecho paterno que defiende su hermano, comparte con Polinice algo de su herencia en lo cual aún se igualan: lo que el Coro entiende como soberbia, la concepción del poder como un atributo que se detenta individualmente y se ejerce a solas. ${ }^{5}$ 
He querido examinar aquí ciertos textos en los que Antón Arrufat despliega su particular idea de la subjetividad, en un contexto en el que las interpelaciones del gobierno revolucionario apuntan a la construcción de un hombre nuevo cuyos atributos este afirma conocer de antemano. Esta ideología tensionada hacia el futuro define las decisiones políticas en el presente que se proponen acabar con los defectos del régimen anterior para lograr la transformación deseada. Arrufat niega este esquema, y al hacerlo lo problematiza al menos en dos aspectos. Por un lado, complejiza la relación con el pasado, que en el discurso oficial se centra alrededor de la exaltación épica y el culto a los héroes - fundamentalmente Martí, en los primeros años, y después de 1967, el Che Guevara. Alejado de esta idea moralizadora del pasado según la cual su rememoración está ligada a la ejemplariedad, Arrufat va a pensarlo en términos de herencia, de algo que es propio y ajeno a la vez y cuyos componentes - lenguajes, gestos, ciudades, formas de hacer - constituyen la materia misma a partir de la cual nos constituimos de modo nunca definitivo. "Ignoro si los pájaros heredan sus nidos y las fieras sus madrigueras, pero nosotros heredamos siempre" (9), ha dicho en El hombre discursivo. La idea de que es posible diseñar una subjetividad sin considerar la presencia del pasado es simplemente inconcebible para Arrufat. Por otro lado, complejiza la doctrina materialista que en el discurso del gobierno revolucionario se ha cristalizado en la convicción de que hay una cierta "esencia" humana cuyo desarrollo "natural" ha sido pervertido y oprimido, pero que puede alcanzar su forma más acabada si es "sometid[a] a estímulos y presiones de cierta intensidad" (Guevara 40): esto es, de una pedagogía que, desde el exterior, sea capaz de liberar las conciencias. Nada más extraño para Arrufat que esta creencia: todo hombre es el ocupante de un lugar que ya ha sido habitado - toda conciencia es ese lugar ocupado ya por otros - y, por tanto, siempre se está de repaso. En este sentido, hay en estos textos que hemos leído aquí un fuerte impulso igualitarista: no hay ningún sujeto ni vanguardia privilegiada que nos haga descubrir el "verdadero" mundo porque que no hay un mundo anterior a nuestra propia praxis colectiva. Es ésta la que lo produce y produce también nuestra propia subjetividad. La herencia de esa realidad fabricada en común - herencia que, como hemos visto, es también apertura a la transformación - aporta la materia con la que se llevan a cabo incluso los acontecimientos más excepcionales de la historia. Ese reconocimiento de lo cotidiano explica el tono anti-épico de los poemas de Arrufat, contrarios a la veneración y la celebración de los grandes hombres. Y permite, también, entender su preferencia por la cita que se atribuye a Heráclito cuando, al ver vacilar a sus visitantes en el umbral de su cocina, los anima a pasar a ese escenario humilde, 
diciéndoles: "Entrad, aquí también hay dioses". ${ }^{6}$ También al lado del fogón y la sartén se manifiesta el poder de los dioses para hacer mundo: la comida, dice el narrador de "La empanada de rosas", es también un modo de producir lo social (Pequeñas cosas 101). Así, la subjetividad que reivindica la poesía de Arrufat no es la de un self que encuentra en el recinto privado, allí donde no rige la ley ni la reprobación moral, la posibilidad de expresarse sin determinaciones externas. Por el contrario, su idea de la subjetividad es indisociable de un rescate de lo común, en su doble acepción: lo que pertenece a todos y es patrimonio de todos, y lo que es del orden de lo cotidiano, de lo ordinario, esto es, que se opone al acontecimiento excepcional. En un momento en el que la palabra "cultura" ha reducido su referente al campo de las instituciones culturales, sus intervenciones y sus políticas, este rescate es también una reivindicación de los procesos de autocreación a través de los cuales los cubanos se han hecho, con el legado de los otros, a sí mismos: "Si miras podrás ver/ que debajo de estas palabras hay otras" (Repaso 19), nos advierte Arrufat en el instante mismo en que hablando, repasa.

Centro de Investigaciones y Estudios sobre cultura y sociedad. CONICET y Universidad Nacional de Córdoba

\section{NOTAS}

$1 \quad$ En su artículo Jesús Barquet enumera los logros de Arrufat en ese momento:

“Es jefe de redacción de la revista Casa de las Américas de 1960 a 1965, recibe la Mención de Teatro en el Premio Casa de las Américas por El vivo al pollo y Mención en Poesía en el mismo premio en 1963 por Repaso final, su teatro es constantemente escenificado ... Su obra se publica ampliamente: en poesía aparecen En claro (1962), Repaso final (1964) y Escrito en las puertas (1968); en narrativa, Mi antagonista y otras observaciones (1963); en teatro, su recopilación Teatro (1963) y Todos los domingos (1965); como editor publica las antologías Cuentos (1964) de Julio Cortázar y Teatro (1964) de Augusto

Strindberg; y en lo referente a crítica y polémica literaria, aparecen numerosos artículos e intervenciones suyas en diversas revistas nacionales" (61).

2 En "El socialismo y el hombre en Cuba", el Che comenta que el Estado cubano está en vías de perfeccionamiento de los procedimientos para la generación de una nueva conciencia social, que se fundan en premisas casi conductistas: "...la masa realiza con entusiasmo y disciplina sin iguales las tareas que el Gobierno fija, ya sean de índole económica, cultural, de defensa, deportiva, etcétera. La iniciativa parte en general de Fidel o del alto mando dela Revolución y es 
explicada al pueblo que la toma como suya. Otras veces, experiencias locales se toman por el Partido y el Gobierno para hacerlas generales, siguiendo el mismo procedimiento. Sin embargo, el Estado se equivoca a veces ... Debemos mejorarla durante el curso de los próximos años, pero en el caso de las iniciativas surgidas en los estratos superiores del Gobierno, utilizamos por ahora el método casi intuitivo de auscultar las reacciones generales frente a los problemas planteados" (36).

3 Por ejemplo, en su libro En claro (1962), pueden leerse los siguientes versos del poema "El viajero", luego recogido junto a otros poemas en Repaso final: "Decía Heráclito que nada permanece. / Pienso que los viajeros pierden su identidad. / Las aguas de los hoteles/ se llevan nuestras manos por el desagüe, / y los días destruyen atareados mis ojos" (Repaso final 25).

4 En su Poética, Aristóteles define la anagnórisis o reconocimiento como "el cambio desde la ignorancia al conocimiento, para amistad o para odio, de los destinados a la dicha o al infortunio" (XI, 1452a), el cual puede producirse con relación a objetos, acciones o personas y, en este último caso, puede serlo de uno mismo, de otro o bien un reconocimiento mutuo. Yendo más allá del sentido aristotélico, para nuestra lectura de estos textos de Antón Arrufat resultan especialmente iluminadoras las posiciones de Terence Cave (1988) y de Philipe Kennedy y Marilyn Lawrence (2008), para quienes la importancia de la anagnórisis tiene que ver no sólo con su función en la resolución de las tensiones de la narración al descubrirse la verdad, sino sobre todo por su capacidad para generar una serie de preguntas que nos enfrentan con la precariedad de los modos en que conocemos y leemos los signos del mundo.

5 Las intervenciones del Coro cuando Etéocles decide batirse contra su hermano sugieren esta interpretación, como cuando dice: "Te estrechas a ti mismo, Etéocles. Tu mano/ en el aire tu otra mano encuentra. / ¡Serás, como él, víctima de la soberbia!/ La soberbia reina en un cuarto oscuro, /con un espejo donde se contempla para siempre. / Aparta ese espejo. Recuerda / que hay otros hombres en el mundo" (Siete contra Tebas 81). Isabelle Torrance ha profundizado en este punto.

6 Las palabras de Heráclito son el primer verso de "En la puerta del hijo" (Escrito en las puertas 12) y el primer renglón de "La empanada de rosas" (De las pequeñas cosas 95). La cita, que vincula cocina y divinidad, es la "puerta" de acceso a un poema acerca de la madre, en el primer caso, y a un pequeño ensayo-relato que discurre en torno a la comida cubana, en el segundo.

\section{OBRAS CITADAS}

AR IS T ót eles. Poética. Trad. y notas de E. Schlesinger. Buenos Aires: Barlovento Editora, 1977. 
AR Rufat, An Tó n. De las pequeñas cosas. Valencia: Pre-Textos, 1997.

-. El hombre discursivo. La Habana: Letras Cubanas, 2005.

—. En claro. La Habana: Ediciones La Tertulia, 1962.

—. Escrito en las puertas. La Habana: Cuadernos Unión, 1968.

—. La caja está cerrada. La Habana: Editorial Letras Cubanas, 1984.

- La huella en la arena: Antología poética. Buenos Aires: La Bohemia, 2000.

—. Los siete contra Tebas. La Habana: Unión de Escritores y Artistas de Cuba, 1968.

- Repaso final (poemas). La Habana: Ediciones Revolución, 1964.

—.Virgilio Piñera: entre él y y yo. La Habana: Unión, 1994.

BARquet, JEsús. "El caso se investiga: Antón Arrufaty Los siete contra Tebas". La

Palabra y el Hombre 115 (2000): 59-69.

BEJE L, E M I Li o. "Antón Arrufat". Escribir en Cuba: entrevistas con escritores cubanos,

1979-1989. Río Piedras: Editorial de la Universidad de Puerto Rico, 1991. 1-14.

CASTRO, FIDEL. "Discurso pronunciado en la inauguración de las obras de San

Andrés de Caiguanabo" 28 enero 1967.

http://www.cuba.cu/gobierno/discursos/1967/esp/f280167e.html

—. "Palabras a los intelectuales" (1961). Revolución, letras, arte. Ed. Virgilio López

Lemus. La Habana: Editorial Letras Cubanas, 1980. 7- 33 .

CAVE, Terence. Recognitions: A Study in Poetics. Oxford: Clarendon P, 1988.

CHENG, Y ING H ONG. Creating the "New Man": From Enlightenment Ideals to Socialist

Realities. Honolulu: U of Hawaii P, 2009.

COMITÉ DIRECTOR DE LA UNIÓN DE ESCRITORES Y ARTISTAS DE CUBA.

“Declaración de la UNEAC". Antón Arrufat. Los siete contra Tebas. La Habana:

Ediciones Unión, 1968. 7-16.

Deleuze, gilles y FÉLix GUATtARi. Mil mesetas. Capitalismo y esquizofrenia.

Valencia: Pre-textos, 1988.

DEleuZe, Gilles. Diferencia y repetición. Buenos Aires: Amorrortu, 2002.

DER RIDA, JA CQUES. Sobre un tono apocalíptico adoptado recientemente en la

filosofía. México: Siglo XXI, 1994.

fornet, a m b Rosio. "A propósito de Las iniciales de la tierra." Casa de las Américas

164 (1987): 148-53.

f o u C A u t, M I C H L L. "Prólogo”. Historia de la locura en la época clásica. México:

Fondo de Cultura Económica, 1988. 4-5.

gONZÁ LEZ e CheVARR Í A, RoBerto. "Biografía de un cimarrón and the Novel of the

Cuban Revolution". Novel: a Forum on Fiction 13.3 (1980): 249-263.

—. "The Humanities and Cuban Studies, 1959-1989." Cuban Studies Since the

Revolution. Ed. Damián Fernández. Gainesville: UP of Florida, 1992. 199-215.

GUEVARA, ERnEST o. "El socialismo y el hombre en Cuba". Revolución, letras, arte.

Ed. Virgilio López Lemus. La Habana: Editorial Letras Cubanas, 1980. 34-48.

KA PCIA, AN T H N Y. Cuba. Island of Dreams. Oxford: Berg Publishers, 2000. 
KenNedy, Philip y LAWRENCE, MARILyn. Recognition: The Poetics of Narrative. Interdisciplinary Studies on Anagnorisis (Studies on Themes and Motifs in Literature, Vol.96). Bern: Peter Lang Publishing, 2008.

MaCD o NA LD, THE o d o RE. Schooling the Revolution. An Analysis of Developments in Cuban Education since 1959. London: Praxis Press, 1996.

mateo palmer, margarita. "Antón Arrufat o la estética de la superposición”. Unión. Revista de literatura y Arte 28 (1997): 16-22.

Miller, Nic ola. "A Revolutionary Modernity: The Cultural Policy of the Cuban Revolution". Journal of Latin American Studies 40 (2008): 675-696.

Pla ó n. La República. Buenos Aires: Emecé Editores, 1945.

St einer, G Eorge. Después de Babel: aspectos del lenguaje y la traducción. México, D.F: Fondo de Cultura Económica, 1980.

tor RANCE, ISA B ELle. "Brothers at War: Aeschylus in Cuba". Alma Parens

Originalis? The Receptions of Classical Literature and Thought in Africa, Europe, the United States, and Cuba. Ed. John Hilton. Oxford: Lang, 2007. 291-316. 